\title{
ARDUINO BASED FIRE DETECTION AND CONTROL SYSTEM
}

\author{
Muhammad Shazali Dauda, Usman Saleh Toro \\ Department of Computer and communication Engineering \\ Abubakar Tafawa Balewa University Bauchi, \\ Bauchi State Nigeria
}

\begin{abstract}
Fire outbreak is a major concern at homes, offices, industries etc. It is dangerous and requires high security and control to avoid destruction of lives and property. One of the preventive measures to avoid the danger is to install an automatic fire alarm detector at vulnerable locations, hence the Arduino based fire alarm detection and control system was proposed. It is capable of automatically detecting heat in a given environment, sound an alarm, switch off mains of the building and also spray water to reduce the intensity of fire. The system uses a DHT 11 sensor, a buzzer, 5v DC (Direct Current) motor, a GSM (Global System for Mobile) Module sim8001 to send SMS (Short Message Service) and a LCD screen 16X2 and Atmeg328p Microcontroller. At the end, the objectives of this project were achieved and the system worked effectively.
\end{abstract}

Keywords - Fire Outbreak, DHT11, SIM 8001, ATMEGA328p and LCD

\section{INTRODUCTION}

Introduction- Ever since mankind first began building structures out of wood rather than stone, fire has been a part of the learning process. In fact, so common have these infernos been throughout history that nearly every major city in the world has been largely burnt to the ground at one time or another in its history. An example of such fire outbreak was in Boston 1872. While not as large a fire as the one in Chicago the year before or the fire that was to ravage San Francisco just over three decades later [2]

Firefighting requires skills in combating, extinguishing, and preventing fires, responding to emergency calls, operating and maintaining fire department equipment and quarters, and extensive training in performing firefighting activities.

The earliest known firefighters were in the city of Rome. In 60 A.D., emperor Nero established a Corps of Vigils (Vigils) to protect Rome after a disastrous fire. It consisted of 7,000 people equipped with buckets and axes, and they fought fires and served as police [3].

In the 4th century B.C., an Alexandrian Greek named Ctesibius made a double force pump called a siphon. As water rose in the chamber, it compressed the air inside, which forced the water to eject in a steady stream through a pipe and nozzle [4]

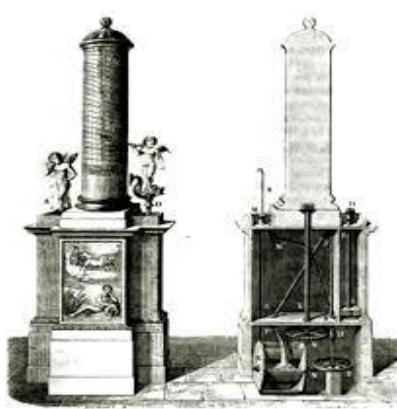

Fig. 1. Ancient Method of Extinguishing Fire, Ctesibius double force pump.

Nowadays, some factories and buildings have proper installation and fire safety and control arrangements such as fire alarm, fire extinguishers, water supply system etc. But the problem is these conventional fire extinguishing systems are not enough to take prompt action during fire outbreak and hence, save life. The best way to reduce these losses is to respond to the emergency situation as quickly as possible. So, there comes the necessity of a standalone fire detection systems. This project therefore seeks to design a microcontroller fire alarm and control system that will continuously monitor the presence of significant amount of heat and activate an alarm and simultaneously switch off the mains of the building, send an SMS alert and extinguish the fire as a safety measure to contain the situation.

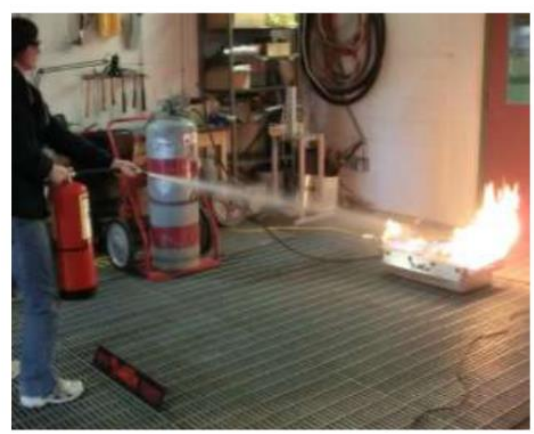

Fig. 2. Conventional system to Extinguish Fire [15]

Problem Statement-- Safety is a crucial consideration in the design of residential and commercial buildings in order to safeguard against loss of life and damage to property. 


\section{International Journal of Engineering Applied Sciences and Technology, 2020 \\ Vol. 4, Issue 11, ISSN No. 2455-2143, Pages 447-453 \\ Published Online March 2020 in IJEAST (http://www.ijeast.com)}

The existing fire alarm system in market nowadays is too complex in terms of its design and structure. Since the system is too complex, it needs regular maintenance to be carried out to make sure the system operates well. Meanwhile, when the maintenance is being done to the existing system, it could raise the cost of the system.

Proposed System-- the project is designed with a low cost and all level users can have one for a safety purpose. This project therefore seeks to design a fire alarm system that will continuously monitor the presence of significant amount of heat and activate an alarm simultaneously switch off the mains of the building, send a Short Message Service(SMS) alert and extinguish the fire as a safety measure to contain the situation.

The rest of the paper is organized as follows. Related work is explained in section II. Proposed system is explained in section II. Experimental results are presented in section IV. Concluding remarks are given in section $\mathrm{V}$.

\section{RELATED WORK}

A number of efforts have been put recently into designing systems that can detect and control fire outbreaks.

Burchan et al. (2019). The paper examines the potential use of fire extinguishing balls as part of a proposed system, where drone and remote-sensing technologies are utilized cooperatively as a supplement to traditional firefighting methods. The system consists of courtingunmanned aircraft system (UAS) to detect spot fires and monitor the risk of wildfire approaching a building via remote sensing, communication UAS to establish and extend the communication channel between scouting UAS and firefighting UAS, and a fire-fighting UAS. One has to be very skillful in controlling drones and also the system is very complex which makes the system unreliable. [8]

Qin et al. (2018). Designed an intelligent smoke alarm system with wireless sensor network using ZigBee. The system consists of a smoke detection module, a wireless communication module, and intelligent identification and data visualization module. The disadvantage of his system is that it is very expensive and complex to design. [7]

\begin{abstract}
Izang et al. (2018). Designed An SMS Based Fire Alarm and Detection System. The system works when fire or gas is detected by the sensors, the Arduino will trigger the GSM module to send SMS, sound the alarm system and trigger the servo motor. The disadvantage of this system is that the servo motor works at an angle of 170 degrees and hence cannot reduce fire outbreak as compared to using a pump motor. [11]
\end{abstract}

Jinan (2018) Designed and Implemented a Factory Security System that consist of a smoke sensor, a GSM (Global
System for Mobile communication) module and a sound module. When the gas leakage is detected, an SMS will be sent to a number. The disadvantage of the system is that there is no device that can stop the gas leakage and hence, when there is fire outbreak the necessary deviceto extinguish the fire is not included in the system which may cost loss of properties. [6]

Poonam et al. (2014). Designedan Intelligent Fire Extinguisher System. the features are intelligent fire detection and suppression, locate the position of fire origin, effective power control of electricity, reporting through an SMS or email and effective usage of water supply, among the sensors used is a gas sensor which detect any type of smoke, this can send a false alarm and hence not reliable. [12]

\section{PROPOSED SYSTEM}

This Chapter Explain about the system Design and construction through Hardware and software development. In addition, the chapter elaborates the hardware and the software stage by stage. All the operations of hardware and software are also included in this chapter

\section{System Architecture}

The system architecture of the automatic Fire alarm and control system can be divided into 8 main Modules. They include:

1. Display Module

2. Microcontroller Module

3. Sensory Module

4. Sound Module

5. GSM Module

6. DC Pump Motor

7. Appliance Module

8. Power Supply Module

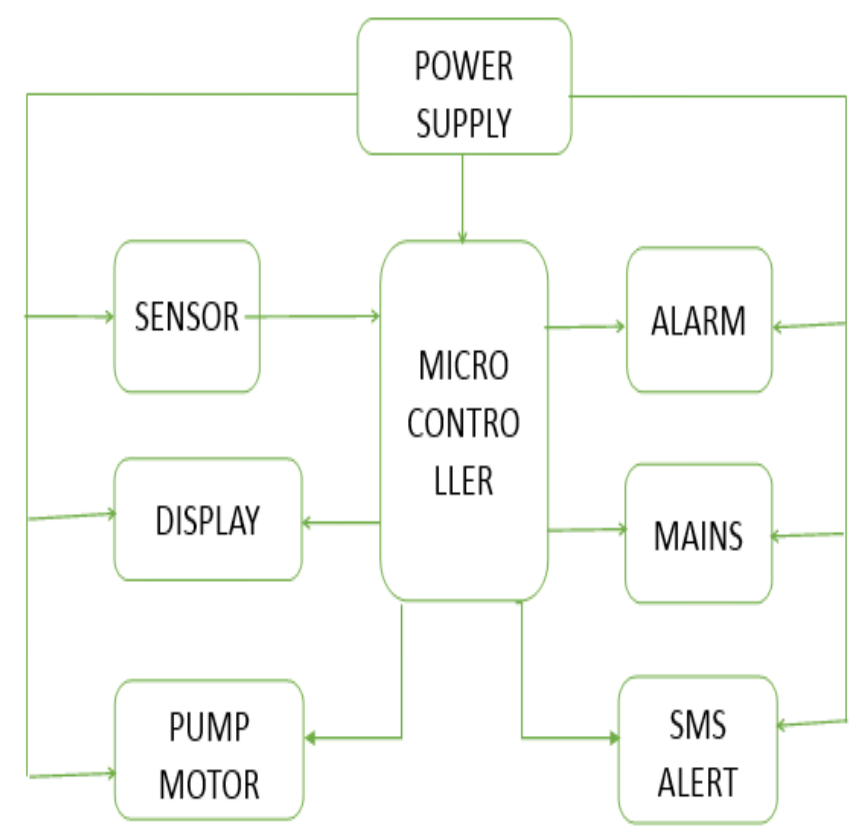

Fig. 3. Block diagram of simple system design 


\section{International Journal of Engineering Applied Sciences and Technology, 2020 \\ Vol. 4, Issue 11, ISSN No. 2455-2143, Pages 447-453 \\ Published Online March 2020 in IJEAST (http://www.ijeast.com)}

1. Display Module. LCD (Liquid Crystal Display) 16X2. As explained earlier, a LCD is an electronic display module. In this project, the LCD is used to display the current temperature of the environment at a temperature less than or equals to 40 degrees Celsius, and when the temperature is greater than or equals to 40 degrees Celsius, it displays the message "Attention pls" then "High Temp detected".

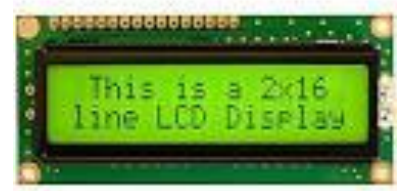

Fig. 4. 16X2 Liquid Crystal Display

2. Micro Controller Module Atmega328p. The microcontroller is a compact microcomputer, designed to control the operation of embedded electronic systems in various applications. Here, it is used to read the environment temperature from the sensor module, display the characters on the display module and switch on or off the necessary pins as per the program uploaded on the microcontroller.

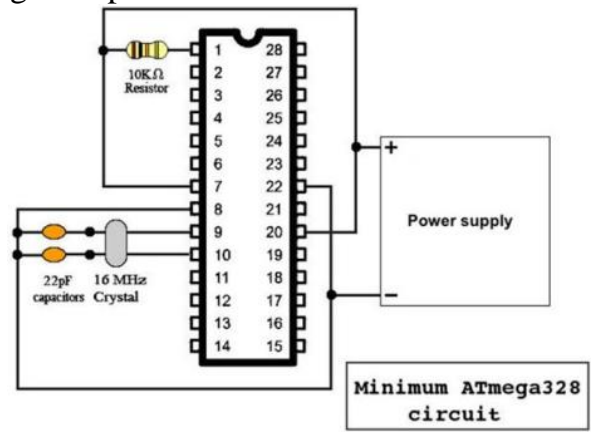

Fig. 5. Atmega 328p Microcontroller

3. Sensory Module. The DHT11 is a basic, -low-cost digital temperature and humidity sensor. It uses a capacitive humidity sensor and a thermistor to measure the surrounding air, and spits out a digital signal on the data pin (no analogue input pins needed). $i \mathrm{t}$ is used to measure the environment temperature and sends it to the microcontroller.

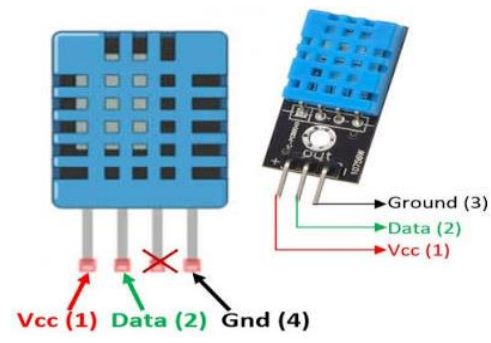

Fig. 6. DHT11 Sensor
4. Sound Module. Buzzer. The buzzer in this circuit is used when microcontroller provides high signal, i.e. when a temperature is greater than or equals to 40 degrees Celsius, the circuit will be completed and the buzzer will start alarming.

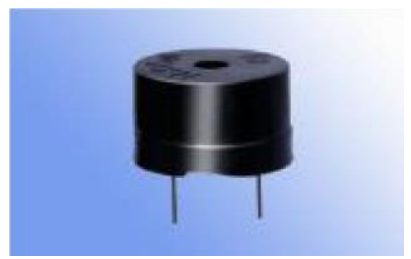

Fig. 7. Buzzer

5. GSM Module. The Module communicates with the microcontroller via MAX232 driver, activated using AT commands. it is used to send a SMS message to a mobile number. The GPRS is configured and controlled via its universal asynchronous receiver transmitter, UART using simple AT commands.

The alert message is sent to distant remote locations using wireless networks (RF Tx /Rx pair),

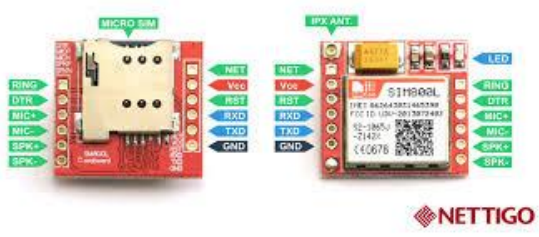

Fig. 8. GSM Module

6. DC Pump Motor. The pump motor is used to generate water from a tank and sprinkle it to the affected area caught on fire. This is done so when a high signal is sent to the pin the motor is connected. The motor is powered through a 12 -volt relay

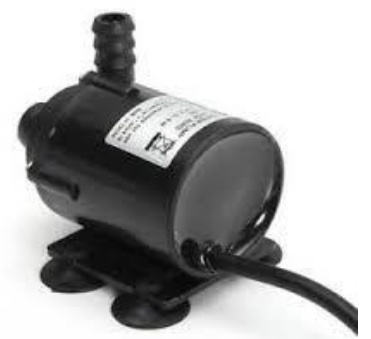

Fig. 9. 5v DC pump motor

7. Power Supply Unit The power supply module was required to supply regulated $5 \mathrm{~V}$ dc to the circuit while plugged to the mains. The components include Step down transformer, Voltage regulator, Capacitors and Diodes 
International Journal of Engineering Applied Sciences and Technology, 2020

Vol. 4, Issue 11, ISSN No. 2455-2143, Pages 447-453

Published Online March 2020 in IJEAST (http://www.ijeast.com)

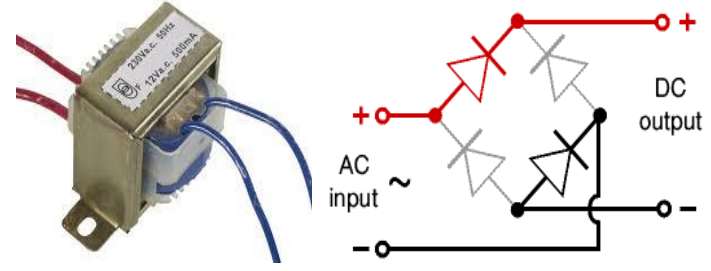

Fig. 10. A 12v Transformer

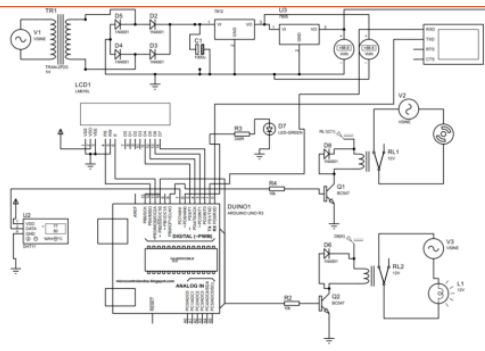

Fig. 11. circuit diagram of the system

\section{Software Design}

The whole system is controlled by a firmware which is implemented in embedded IC which was built by a compiler (Arduino). Then the program is downloaded to the 8-bit Atmega328P microcontroller. Figure 28 shows the Program Flowchart.

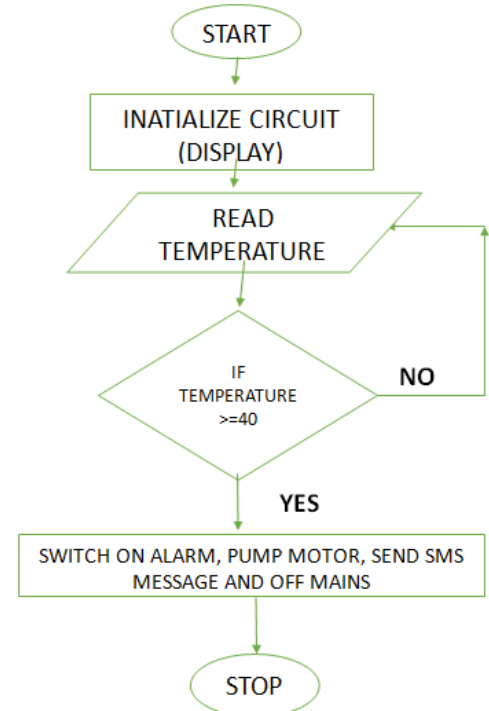

Fig. 12. Software Design

\section{EXPERIMENT AND RESULT}

This chapter presents the description of test performed on the various sections of the overall system and their corresponding results as well as the result of the overall system. In order to verify the functionality of the system, each component was tested individually.
Test on Power Supply Unit (PSU)

The following results were obtained during power supply test

Table 1 power supply test result

\begin{tabular}{|l|l|l|}
\hline Transformer & Simulation & Breadboard \\
\hline Input voltage & $240 \mathrm{v}$ & $221 \mathrm{v}$ \\
\hline $\begin{array}{l}\text { Rectified LM7805 Input } \\
\text { Voltage }\end{array}$ & $11.05 \mathrm{v}$ & $13.59 \mathrm{v}$ \\
\hline $\begin{array}{l}\text { Rectified LM7805 Output } \\
\text { Voltage }\end{array}$ & $5.01 \mathrm{v}$ & $5.09 \mathrm{v}$ \\
\hline $\begin{array}{l}\text { Rectified LM7812 Input } \\
\text { Voltage }\end{array}$ & $11.40 \mathrm{v}$ & $13.56 \mathrm{v}$ \\
\hline $\begin{array}{l}\text { Rectified LM7812 Output } \\
\text { Voltage }\end{array}$ & $11.05 \mathrm{v}$ & $12.09 \mathrm{v}$ \\
\hline $\begin{array}{l}\text { Rectified LM317 Output } \\
\text { Voltage }\end{array}$ & 3.67 & $3.98 \mathrm{v}$ \\
\hline $\begin{array}{l}\text { Rectified LM317 Input } \\
\text { Voltage }\end{array}$ & 5.01 & 5.09 \\
\hline
\end{tabular}
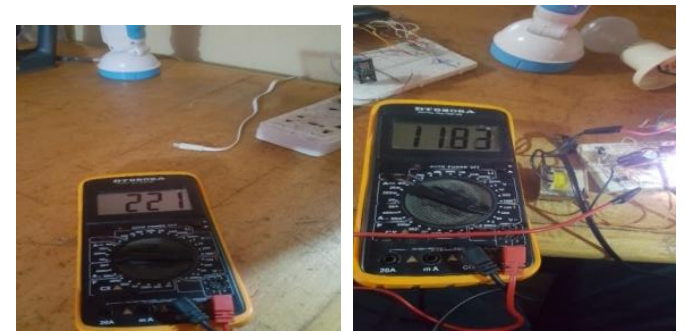

Fig. 13. transformer input and output voltage (Breadboard)

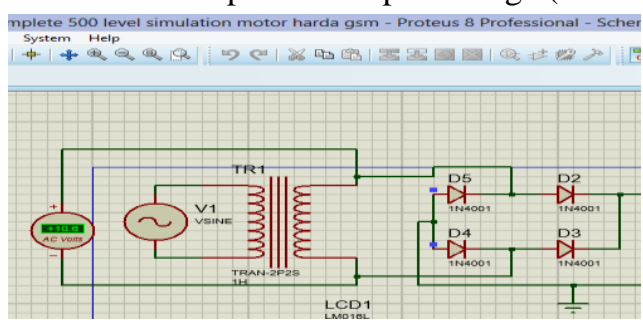

Fig. 14. transformer output voltage (Simulation)

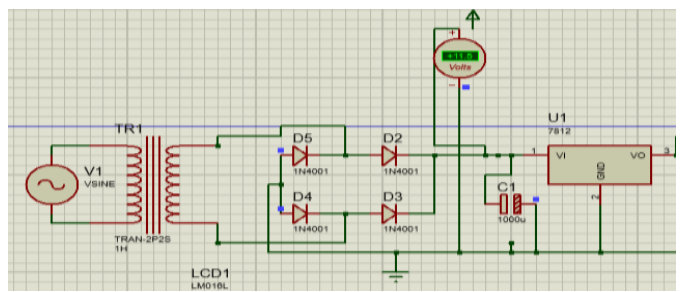

Fig. 15. Rectified LM7812 Input Voltage (Simulation) 


\section{International Journal of Engineering Applied Sciences and Technology, 2020 \\ Vol. 4, Issue 11, ISSN No. 2455-2143, Pages 447-453 \\ Published Online March 2020 in IJEAST (http://www.ijeast.com)}

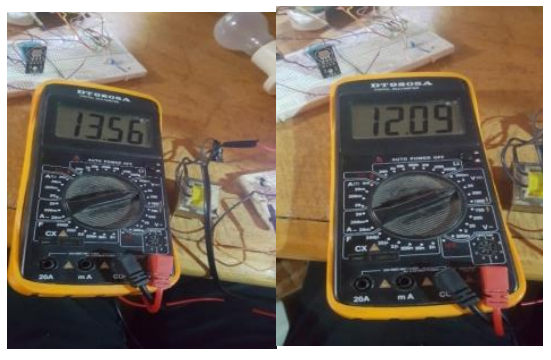

Fig. 16. Rectified LM7812 Input and output Voltage (Breadboard)

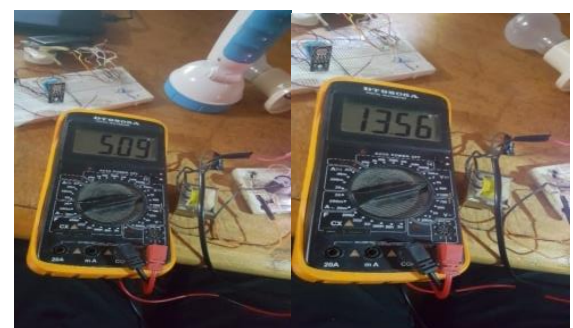

Fig. 17. Rectified LM7805 Input and output Voltage (Breadboard)

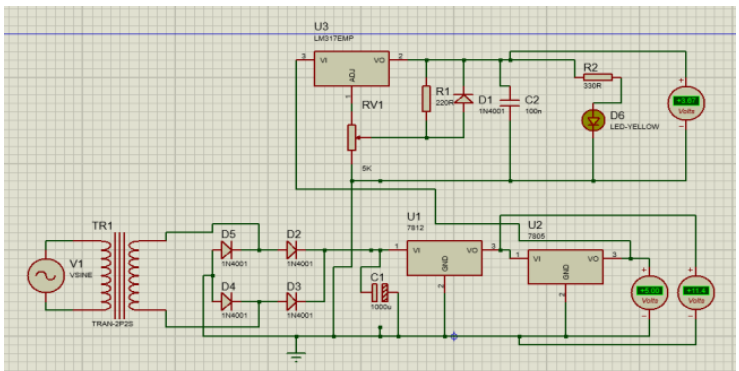

Fig. 18. Rectified LM7812, LM7805 and LM317 output voltage

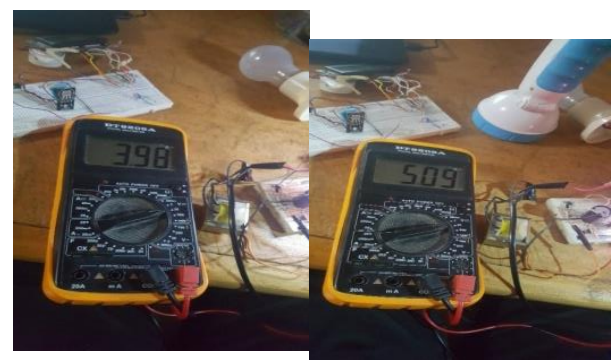

Fig. 19. Rectified LM317 Input and output Voltage (Breadboard)

Table (1) above shows the results obtained from the tests carried out on power supply unit from the circuit. The test results are of two categories; simulation voltage test results and breadboard voltage test results. The simulation transformer input voltage couldn't be found from the software but an alternative of it was used, while for the simulation transformer output voltage, the voltage varies by. 1.23 volt.
Also for the regulators (LM7812, LM7805, LM317), it was observed that the breadboard input voltage value of the regulator varies from simulation voltage value and the same thing applies to the output values of the regulators. The reason for these variations might be due to transformer input voltage which usually varies between $200 \mathrm{v}$ to $240 \mathrm{v}$.

The theoretical laws stated have some assumptions in order to obtain ideal value of AC Voltage source through measurement such as constant pressure, temperature, mechanical strains etc. But when experiment is performed and current passes through the conductor, it leads to heating up of conductor and temperature does not remain constant does leading to some error.

\section{Test on Sound Module (Buzzer)}

Table 2 Test Result on sound Module

\begin{tabular}{|c|c|c|}
\hline Buzzer & Simulation & Breadboard \\
\hline $\begin{array}{c}\text { Turn On Time } \\
\text { Taken }\end{array}$ & $14.20 \mathrm{~s}$ & $13.03 \mathrm{~s}$ \\
\hline
\end{tabular}

On this module, the difference between the time taken for the alarm to sound in simulation is 1,17 seconds faster. In the simulation, an LED was used to serve as the sound module since the simulation software does not sound via the speakers.

\section{Appliance Module}

Table 3 Test result on Appliance module

\begin{tabular}{|ll|l|l|}
\hline Lamp & & Simulation & Breadboard \\
\hline $\begin{array}{l}\text { Turn Off } \\
\text { Taken }\end{array}$ & Time & $15.82 \mathrm{~s}$ & $13.03 \mathrm{~s}$ \\
\hline
\end{tabular}

From the result obtained, the result from breadboard is 2.79 seconds faster than the result from simulation. This is because during the simulation, the relay and lamp used are animated, therefore took time to activate. Also the activation of the lamp and relay depends on the speed of the computer.

\section{GSM Module.}

Table 4 Test Result on GSM module

\begin{tabular}{|l|l|l|}
\hline Sim 800L & Simulation & Breadboard \\
\hline $\begin{array}{l}\text { Message Sent Time } \\
\text { Out }\end{array}$ & $4.07 \mathrm{~s}$ & $15.36 \mathrm{~s}$ \\
\hline
\end{tabular}

Based on the results obtained from the test carried out, it was observed that the text SMS received from simulation was 11.29 seconds faster than the result obtained from breadboard, and this is because during simulation a serial monitor was used to view the text message sent since GSM module cannot display while a mobile phone was used to receive the text message when testing on bread board.

\section{Display Module.}

Table 5 Test Result on Display module

\begin{tabular}{|l|l|l|}
\hline $\begin{array}{l}\text { Liquid Crystal } \\
\text { Display (LCD) }\end{array}$ & Simulation & Breadboard \\
\hline
\end{tabular}




\section{International Journal of Engineering Applied Sciences and Technology, 2020 \\ Vol. 4, Issue 11, ISSN No. 2455-2143, Pages 447-453 \\ Published Online March 2020 in IJEAST (http://www.ijeast.com)}

\begin{tabular}{|l|l|l|}
\hline $\begin{array}{l}\text { Temp less than } \\
\text { 50 degrees }\end{array}$ & $\begin{array}{l}\text { Displays } \\
\text { "current } \\
\text { temperature and } \\
\text { humidity" }\end{array}$ & $\begin{array}{l}\text { Displays } \\
\text { current } \\
\text { temperature } \\
\text { and humidity }\end{array}$ \\
\hline $\begin{array}{l}\text { Temp greater } \\
\text { than 50 degrees }\end{array}$ & $\begin{array}{l}\text { Attention pls } \\
\text { high temp detect }\end{array}$ & $\begin{array}{l}\text { Attention pls } \\
\text { high temp } \\
\text { detect }\end{array}$ \\
\hline Text Displayed & $\begin{array}{l}\text { High } \\
\text { temperature } \\
\text { detected }\end{array}$ & $\begin{array}{l}\text { High } \\
\text { temperature } \\
\text { detected }\end{array}$ \\
\hline
\end{tabular}

At a temperature less than 50 degrees Celsius, the LCD displays the current room temperature in both simulation and breadboard, while at a temperature equal to or greater than 50 which is the threshold degrees Celsius, the LCD displays "Attention pls high temp detect". The reason why the LCD dose not display the text in full is because it can display only sixteen characters on a row and two characters in a column. The message displayed as SMS on mobile phone and serial monitor was "High Temperature Detected"

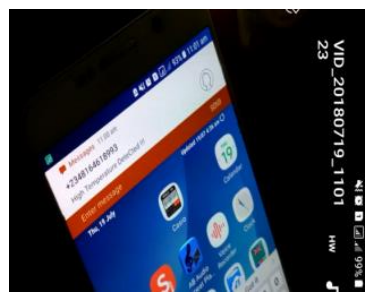

Figure 20 Message Received From The Gsm Module

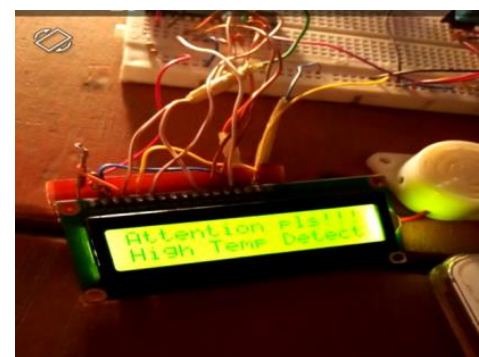

Fig. 21. Result at Temp Eqaul To Or Greather Than 40 Degrees Celsius

\section{Pump Motor}

Table 6 Test result on pump Motor

\begin{tabular}{|l|l|l|}
\hline 5v Pump Motor & Simulation & Breadboard \\
\hline $\begin{array}{l}\text { Motor Start } \\
\text { Time }\end{array}$ & $14.07 \mathrm{~s}$ & $5.36 \mathrm{~s}$ \\
\hline
\end{tabular}

\section{CONCLUSION}

In this work, an attempt has been done to design a fire alarm system using Temperature sensor and Micro controller for efficient use of electricity. It will help to reduce the wastage of electricity, save lives, reduce percentage of accident and reduce waste of electric appliance. The results obtained from the measurement have shown that the system perform well under all the conditions.

The main objective of this project has been to design a circuit that detects high temperature and consequently triggers an alarm, switch off the mains of the building, send SMS message and extinguish the fire. These objectives were met since the systems works effectively.

\section{REFERENCE}

1. Adekunle A., Umanah I.I., Ibe K.E. and Imonikosaye M.R. (2018) Statistical analysis of fire outbreaks in homes and public buildings in Nigeria. A Case Study of Lagos State, (pp. 21 - 30).

2. Amy, T., et al. (2019) Boston fire of 1872.encyclopedia of world history. Retrieved from https://www.britannica.com/event/Boston-fire-of$\underline{1872}$

3. Sarah, B. ( 2017) The great fire of nero and the ancient history of firefighting. Retrieved from https://www.forbes.com/emperor-nero,

4. Erik, A.. Influential innovator. Ctesibius, (2016).

5. Huang, Y., Zhang, W., Dai, X., Zhao Y. (2012). Study on water-based fire extinguishing agent formulations properties. International Symposium on Safety Science and Technology, (pp. 650 - 654)

6. Shehab, J. N. (2018) Design and Implementation of Factory Security System. (PP. 162 - 171)

7. Qin, W. Jiashuo, C. and Chuang, Z. (2018) Intelligent Smoke Alarm System with Wireless SensorNetwork Using ZigBee, (pp. 1 - 10)

8. Aydin, B., Selvi, E., Tao, J. and Starek, M. J. (2019) Use of Fire-Extinguishing Balls for a Conceptual System of Drone-Assisted Wildfire Fighting, (PP.1 15)

9. Bahrepour, M., Meratnia, N. and Havinga, P. (n,d).A Survey From Wireless Sensor Network Perspective, Automatic Fire Detection.

10. Shin-Juh, C., Chris, H., Kristen A. P. and André, M. (2007) Fire detection using smoke and gas sensors, (PP. 2 - 19)

11. Izang, A. A., Ajayi, S.W. Onyenwenu, C. B. and Adeniyi. F.(2018) An SMS Based Fire Alarm and Detection System,.(pp. 58 - 61)

12. Sonsale, p., Gawas, R., Pise, S. and Kaldate, A. (2014). Intelligent Fire Extinguisher System. (pp. 59 61)

13. Warmack, R. J., Dennis, W. and Shane, F. (2015). Using Linear Discriminant Analysis. Smart Smoke Alarm, FEMA (5 - 30) 
Published Online March 2020 in IJEAST (http://www.ijeast.com)

14. Mahzan, N. N., Enzai, N. I. M., Zin, N. M. and Noh, K. S. S. K. M. (2012). Design of an Arduino-based home fire alarm system with GSM module. (pp. 1 - 8)

15. Poole, B. et al (2012) Ordinary People and Effective Operation of Fire Extinguishers. (pp. 08 - 37)

16. Scandella, F. (2012) Feeling the heat. Fire Fighters.(pp.08-54) 